\title{
Difference Research on Visitor Satisfaction of Tourism Shopping in Rural Tourism \\ —— the Case of Tourism Shopping around \\ Changsha City
}

\author{
Xianzhai Fang \\ XinyangUniversity, Xinyang, 467400, China
}

\begin{abstract}
The Chinese tourism shopping is a weak link, especially the rural tourism shopping, which is specially worth researching. This paper got abundant data about the Changsha suburb rural tourists by sample investigation. After analyzing the data, the author found the characteristics of rural tourists' level of tourism shopping satisfaction are that feminine tourist shopping extent is smaller than the male; their shopping custom are coincident with their age; the high educated have less satisfaction than the low; the shopping satisfaction is relatively to the income; there are obvious differences between the household income.

Key words: rural tourism, tourism shopping, visitor satisfaction, Changsha
\end{abstract}

\section{Introduction}

Tourism, which is the modern economy industry that is based on intangible services 
and tangible goods, satisfies consumer's needs for material and spiritual of higher level.Under the condition of the rapid growth of national economy,only 10 years from 2005 to 2015 , the average growth rate of domestic tourism income has reached $14.99 \%$ and the average growth rate of tourist foreign exchange income has reached $14.35 \%$ respectively. The two rates surpass the growth rate of GDP, the tourism industry has become one of the fastest industry of the national economy.In the world, China tourist foreign exchange income and tourist arrivals has reached the world's highest in 2015, China has become tourism power.Since China wants to go from a tourism country to a strong tourism country and achieves a tourism revenue of 3, 6 trillion yuan in 2020,it is necessary to have an average growth rate of $11 \%$ every year of tourism.Not only with the development of the quality but also with the improvement of the quality which could balance the tourism development make up the high speed of development.In China,for a long period, no matter rural or urban tourism, the sales of tourism commodity has been the weak link of tourism development and China's tourism commodity accounts for about $20 \%$ of tourism income for a long time.Tourism shopping in tourism as a proportion of the total consumption is regarded as the tourism construction of a country and the important dimensions of tourism consumption level.Therefore, with the development of tourism commodities as a breakthrough,the Chinese national culture as the basis, the technology as the power,there is the new path to explore China's tourism industry.

Tourism activities are composed of the six basic elements by"food, accommodation, transportation, tour, shopping, entertainment" . In all the elements of the tourism consumption,

"shopping" possesses fairly plasticity and space that could be expanded as one of the biggest demand elasticity.With the development of rural tourism, rural tourism has played an important role in China tourism.Shopping expenditure of the rural tourism in all the rural tourism spending is still low and the proportion of total expenditure is lower than those of city tourism shopping.Taking an example of "XiDi, hong cun",one of the rural tourism that develops better, since it has been developed and managed,the effect is remarkable, the villagers has a strong sense of goods sales of investment and souvenirs are comparatively integrated.According to the survey, the package price is 680 yuan per person and 25.4 yuan per person of shopping. Those two expenses make up 3.7\% the whole expenses.[1].Other shopping 
goods might be lower in the rural tourism market as well as the case of XiDi, hong cun.Therefore, the development of rural tourism commodity becomes even more important.

\section{The research overview}

Chinese scholars' study of tourism commodities began after the reform and opening up.Over the past years,Many scholars make some related researches for tourism commodities from several aspects,such as the production,design and sales of the tourist commodity, tourism commodity market,development about regional tourism commodity.Wu Ganying(1992)discusses the relationship between the tourism purchasing psychology and the productions and sales of tourism commodity[2].Ding Jihua(1996)put forward the view that make Shanghai as the distribution center of tourism commodity by the centralized advantage in traffic, information, people, finance and other native aspects[3].Huang Jiyuan(1999)study about marketing strategy of tourism commodity[4].Zhang Lili(2003)put forward that the packaging design of tourism commodity should reflect the communion of characteristics about local ethnic and times spirit.At the same time,we could shape the image of tourism products through serial packaging design[5].Yan Min(2004)analyzed situation of tourism commodity market in JiangXi and put forward corresponding development countermeasure[6].In recent years, the study about the tourism commodities have a tendency of interdisciplinarity.For example,Zhang Xiaoping(2001) studied about the development of tourism handicraft from the perspective of tourism anthropology.The author took the development of tourism handicraft in yunnan as the examples, the article discussed about the problems such as cultural authenticity,culture commodity, cultural connotation.Shi Meiyu(2003)also made deep study of tourism shopping from the perspective of cultural and put forward the theoretical framework of research about tourism shopping[7]. On the whole,China's academia had certain accumulation about the study of tourism commodities.Most of the scholars' study in this field involves all aspects of tourism commodity, namely the production, design, sales, varing from consumers to the government and various stakeholders.However,there is more empirical research and less theoretical research,meantime, there is more qualitative analysis and less quantitative 
analysis.The paper make qualitative analysis of rural tourism commodity market of Changsha that is based on the investigation and the author expected to explore the characteristics and significance of rural tourism commodity market in Changsha.

\section{Investigation and survey method}

The article based the systematic thought as the instruction,adopting the studying methods of questionnaire survey, data statistics, combing the quantitative analysis with qualitative analysis,combing the macroscopic with the microscopic research and combing the dynamic analysis with static analysis.

This paper takes the rural resorts tourists surrounding Changsha as the investigation object from March,2014.It also takes questionnaire survey,field visit and the interview to accumulate a lot of basic data.Since we handed out 1500 questionnaires and 1068 valid questionnaires among them, getting the efficient of 71 . $2 \%$, the questionnaire survey is smooth.In this sample, the gender structure is balanced, including 587 men whom were $54 \%$ and 500 women whom were $46 \%$.From the age structure in the tourists of rural tourism, aged 25 to 44 (43.97\%), the old man and child is less, accounting for $3.40 \%$ and $7.64 \%$,aged 15 to 24 (20.42\%), aged 45 to $64(24.56 \%)$.When we Looked from the degree of education, primary school and the following accounted for $2.21 \%$,junior high school accounted for $14.63 \%$, high school and technical secondary school accounted for $31.09 \%$, junior college or bachelor degree accounted for $45.72 \%$, graduate students and the above accounted for $6.35 \%$.From the family per capita income, monthly income that is 499 yuan and the following accounted for 4.78\%,500-999 yuan (18.12\%), 1000-1999 yuan (40.94\%), 2000-2999 yuan(25.94\%), 3000 yuan of above accounted for $10.21 \%$.From the professional, including 85 workers, 124 students, 194 civil servants, 47 farmers, 131 teachers, 129 professional and technical personnel,127 enterprises and management personnel , 134 service staff or sales staff, 89 people from retiree and other 27 people.They covers all occupations basically. 


\section{Related concepts}

Domestic scholars have not yet reached a consensus about the concept of tourism commodity, even the unified name.If there is a "tourist goods" or "souvenirs", most scholars call it "tourist commodities". This situation is not conducive to academic exchanges and influences the productions and sales practice by tourism workers.Miao xueling has a point that tourism commodities is designed for tourists, it is anything that the tourists buy for travel or anything possess regional culture characteristics in the process of tourism [8].

Domestic have their limitations on the study of tourist shopping,that the most scholars emphasize that shopping is a kind of economic behavior, emphasize its economic properties and ignore the cultural characteristics. so it is difficult to explain some shopping behavior of tourists.Therefore,Shi meiyu thought that shopping behavior refers to the economic and cultural behavior that the tourists made for travel or the behavior of purchasing all kinds of the physical commodity in tourism activities in his doctoral thesis. It includes not only the special shopping tourism behavior but also all the behavior that related to shopping in tourism[9].

\section{The market investigation and analysis of tourism commodity in Changsha rural}

In the design of questionnaire about the rural tourism in Changsha,we design the related problems such as that "your evaluation for tourist shopping of rural tourism surrounding Changsha ", The answer adopted the way of "5 dividing scale" , which are quite satisfied,satisfied,general satisfied,not satisfied and very dissatisfied", we made a cross-over analysis of the above result with gender, age, culture level, occupation and family income per capita.Then,we drew the following conclusions about tourism shopping satisfaction of rural tourists in Changsha:

\subsection{Differentiation between shopping satisfaction and gender of rural tourists}

Judging from the investigation, rural tourists' cognition to "tourism shopping satisfaction of rural tourists in Changsha" don't differ merely in gender.That the proportion of the choice that men and women tourists making for tourism shopping 
satisfaction of rural tourists are almost the same in the five divides.Men or women tourists'satisfaction on shopping is concentrated on the two options of"satisfied",men(38.0\%),women (43.3\%), and "general" ,men(39.1\%),women(43.3 $\%)$.Meticulous, the women option of "very satisfied" (9.3\%)is lower than the men whom the percentage is $9.8 \%$.However,the females' option of "very dissatisfied" $(0.5 \%)$ is higher than $\operatorname{men}(0.2 \%)$, which refers that women rural tourists have stronger shopping desire than men.See table 1.

Table 1 The cross analysis of shopping satisfaction and gender of rural tourists

\begin{tabular}{|l|l|l|l|l|l|}
\hline & $\begin{array}{l}\text { quite } \\
\text { satisfied }\end{array}$ & satisfied & $\begin{array}{l}\text { general } \\
\text { satisfied }\end{array}$ & $\begin{array}{l}\text { not } \\
\text { satisfied }\end{array}$ & $\begin{array}{l}\text { very } \\
\text { dissatisfied }\end{array}$ \\
\hline women & $9.3 \%$ & $\begin{array}{l}39 . \\
\%\end{array}$ & $43.3 \%$ & $7.8 \%$ & $0.5 \%$ \\
\hline men & $9.8 \%$ & $\begin{array}{l}38 . \\
\%\end{array}$ & $43.3 \%$ & $8.7 \%$ & $0.2 \%$ \\
\hline
\end{tabular}

5.2 Differentiation between shopping satisfaction and age of rural tourists

Among the rural tourists in Changsha who have received the investigation, more than $80 \%$ of the rural tourists think that the rural tourism shopping are "satisfied" and "general satisfied", the percentage of the "satisfied" is lower than the "general satisfied",which explained that there are a lot of room for improvement in the rural tourism shopping.Basing on the statistical data by age, the rural tourists whose age that " $\leqslant 14 "$ have more satisfaction in the process of shopping, among whom "very satisfied" accounted for $18.9 \%$.This satisfaction is the highest in all ages, but "not satisfied" and "very dissatisfied" are $0 \%$ that are low in all ages. The reason may be that the people" $\leqslant 14$ " are students, they have too much school courses normally that they have no time to go out for travel.They have fresh desire for tourism shopping so the degree of satisfaction is higher.The lowest degree of satisfaction in rural tourists differs from "15 to 24 ", and the number of "not satisfied" and "very dissatisfied" accounted for $10.6 \%$ and $3.3 \%$ respectively, which are two of the highest, thus reflecting that young rural tourists are not satisfied with the rural 
tourism shopping the most, which conforms to the young peoples' shopping habits.In an item of "very satisfied", the tourists whose satisfaction degree is lowest in rural tourism shopping are those older people whose ages are " $\geqslant 65 "$, accounting only for $7.2 \%$, which shows that the elderly in the rural tourism shopping are more picky.In general,the tourists' shopping satisfaction in rural tourism merely conform to their shopping habits in different age groups.However,there exists strong differentiation. See table 2 .

Table 2 The cross analysis of shopping satisfaction and age of rural tourists

\begin{tabular}{|c|c|c|c|c|c|}
\hline & $\begin{array}{l}\text { very } \\
\text { satisfied }\end{array}$ & satisfied & $\begin{array}{l}\text { general } \\
\text { satisfied }\end{array}$ & $\begin{array}{l}\text { not } \\
\text { satisfied }\end{array}$ & $\begin{array}{l}\text { very } \\
\text { dissatisfied }\end{array}$ \\
\hline$\leqslant 14$ & 18. $9 \%$ & $\begin{array}{ll}37 & 8 \\
\% & \end{array}$ & 43. $3 \%$ & $0 \%$ & 0 \\
\hline $\begin{array}{l}15- \\
24\end{array}$ & 8. $0 \%$ & $\begin{array}{l}30 \cdot 3 \\
\%\end{array}$ & 47. $8 \%$ & $10.6 \%$ & 3. $3 \%$ \\
\hline $\begin{array}{l}25- \\
44\end{array}$ & $10.8 \%$ & $\begin{array}{l}42 \cdot 3 \\
\%\end{array}$ & $38.7 \%$ & 8. $2 \%$ & 0 \\
\hline $\begin{array}{l}45- \\
64\end{array}$ & $9.7 \%$ & $\begin{array}{l}40 \cdot 1 \\
\%\end{array}$ & $41.4 \%$ & $6.8 \%$ & 1. $0 \%$ \\
\hline$\geqslant 65$ & 7. $2 \%$ & $\begin{array}{l}39 \cdot 8 \\
\%\end{array}$ & 43. $4 \% \%$ & 8. $4 \%$ & 1. $2 \%$ \\
\hline
\end{tabular}

\subsection{Differentiation between shopping satisfaction and education degree of rural tourists}

In stratification of culture degree,the rural tourists' shopping satisfaction have a tendency for the two items of "satisfied" and "general satisfied".The highest degree of satisfaction refers to the tourists who get the education degree of junior high school, accounting for $86.7 \%$, which is quiet high. The lowest is $77.9 \%$,referring to 
the tourists whose degrees are master or above master. In the option of "very satisfied",the shopping satisfaction of primary school education and the below reaches $25.0 \%$, while the lowest shopping satisfaction is the crowd who have a higher cultural level that possess master degree or above.The"very satisfied" accounted only for $7.4 \%$.As cultural degree rise,the percentages of the crowd of "very satisfied" fall in rural tourism shopping basically.Because in the option "very dissatisfied",the number of people of primary school or the below, junior high school and master or the above is zero, the number is not convenience to be compared.Meantime, in the option "not satisfied",the tourists whose degrees are master or above master reaches $14.7 \%$,yet the tourists whose degrees are junior high school reaches $3.4 \%$ only.As cultural degree rise, the percentages of the crowd of "not satisfied" raise in rural tourism shopping basically.In summary, the rural tourists of higher education level have lower shopping satisfaction in rural tourism shopping,the rural tourists of lower education level have higher shopping satisfaction in rural tourism shopping.Under normal circumstances, the rural tourists who possess higher educational level have higher income, stronger shopping desires and better shopping consumption ability.Therefore, we should pay attention to tourism commodity quality,cultural characteristics and local characteristics in the development of commodity in rural tourism and etc, we should also improve their tourism shopping satisfaction. See table 3.

Table 3 The cross analysis of shopping satisfaction and education degree of rural tourists

\begin{tabular}{|l|l|l|l|l|l|}
\hline & $\begin{array}{l}\text { very } \\
\text { satisfied }\end{array}$ & satisfied & $\begin{array}{l}\text { general } \\
\text { satisfied }\end{array}$ & $\begin{array}{l}\text { not } \\
\text { satisfied }\end{array}$ & $\begin{array}{l}\text { very } \\
\text { dissatisfied }\end{array}$ \\
\hline $\begin{array}{l}\text { the primary } \\
\text { school }\end{array}$ & $25.0 \%$ & $\begin{array}{c}25.0 \\
\%\end{array}$ & $43.8 \%$ & $6.2 \%$ & 0 \\
and the below & $9.9 \%$ & 38.4 & $48.3 \%$ & $3.4 \%$ & 0 \\
junior high \\
school
\end{tabular}




\begin{tabular}{|l|l|l|l|l|l|}
\hline $\begin{array}{l}\text { high school or } \\
\text { technical }\end{array}$ & $11.4 \%$ & 38.2 & $41.5 \%$ & $8.3 \%$ & $0.6 \%$ \\
$\begin{array}{l}\text { secondary } \\
\text { school }\end{array}$ & $8.4 \%$ & $\begin{array}{l}37.4 \\
\%\end{array}$ & $44.6 \%$ & $9.2 \%$ & $0.4 \%$ \\
$\begin{array}{l}\text { college or } \\
\text { bachelor degree }\end{array}$ & $\begin{array}{l}3.4 \% \\
\text { master or the } \\
\text { above }\end{array}$ & $\begin{array}{l}4.4 .5 \\
\%\end{array}$ & $29.4 \%$ & $14.7 \%$ & 0 \\
\hline
\end{tabular}

\subsection{Differentiation between satisfaction and occupation of rural tourists}

According to the aspect of the shopping satisfaction in rural tourism, on one hand,the number of other workers is less, on the other hand,the number of people who choose "not satisfied" and "very dissatisfied" are zero, therefore,we do not make analysis.In the option of "most satisfied" in rural tourism shopping, the highest percentage $(18.8 \%)$ are farmers and workers (18.2), the minimum percentage $(4.0 \%)$ are professional and technical personnel and teachers $(7.8 \%)$, the degree of "very satisfied"among civil servants is high,which is up to $13.0 \%$.In the two options of "satisfied" and "general satisfied" in rural tourism shopping,the occupations which account for over $80 \%$ of profession are retirees $(86.4 \%)$, professional and technical personnel $(85.7 \%)$, enterprise management personnel $(84.6 \%)$ and service or sales staff $(83.5 \%)$, the two lowest are farmers $(71.5 \%)$ and workers $(72.7 \%)$.In the option of "very dissatisfied", because there are only four people, including one student, two professional and technical personnel and one service or sales, other professional don't make this option, so there is no representative.In the option of "not satisfied" in the rural tourism shopping,the highest percentage is the student $(13.1 \%)$, followed by farmers $(12.5 \%)$ and teachers $(12.5 \%)$, the lowest percentage is the retirees $(2.3 \%)$ and service or sales staff $(4.5 \%)$.Overall,peasants, workers and retirees who have low income show higher satisfaction in rural tourism shopping,yet the civil servants also show high satisfaction because of the special identity, while the teachers, professional and 
technical personnel, business managers, students and other professional reported lower satisfaction. See table 4.

Table 4 The cross analysis of shopping satisfaction and occupation of rural tourists

\begin{tabular}{|c|c|c|c|c|c|}
\hline & $\begin{array}{l}\text { very } \\
\text { satisfied }\end{array}$ & satisfied & $\begin{array}{l}\text { general } \\
\text { satisfied }\end{array}$ & $\begin{array}{l}\text { not } \\
\text { satisfied }\end{array}$ & $\begin{array}{l}\text { very } \\
\text { dissatisfied }\end{array}$ \\
\hline workers & 18. $2 \%$ & $\begin{array}{l}31 \cdot 8 \\
\%\end{array}$ & $40.9 \%$ & 9. $1 \%$ & 0 \\
\hline students & 8. $2 \%$ & $\begin{array}{l}23 \cdot 0 \\
\%\end{array}$ & 54. $9 \%$ & 13. $1 \%$ & $0.8 \%$ \\
\hline civil servants & 13. $0 \%$ & $\begin{array}{l}37 \cdot 3 \\
\%\end{array}$ & $40.4 \%$ & 9. $3 \%$ & 0 \\
\hline peasants & 18. $8 \%$ & $\begin{array}{l}12 \cdot 5 \\
\%\end{array}$ & $56.2 \%$ & 12. $5 \%$ & 0 \\
\hline teachers & 7. $8 \%$ & $\begin{array}{l}48 \cdot 4 \\
\%\end{array}$ & $31.3 \%$ & 12. $5 \%$ & 0 \\
\hline $\begin{array}{l}\text { professional and } \\
\text { technical } \\
\text { personnel }\end{array}$ & 4. $0 \%$ & $\begin{array}{l}44 \cdot 4 \\
\%\end{array}$ & 41. $3 \%$ & 8. $7 \%$ & 1. $6 \%$ \\
\hline $\begin{array}{l}\text { enterprise } \\
\text { management }\end{array}$ & 8. $1 \%$ & $\begin{array}{l}42 \cdot 3 \\
\%\end{array}$ & 42. $3 \%$ & 7. $3 \%$ & 0 \\
\hline $\begin{array}{l}\text { service or sales } \\
\text { staff }\end{array}$ & 11. $3 \%$ & $\begin{array}{l}42 \cdot 1 \\
\%\end{array}$ & 41. $4 \%$ & 4. $5 \%$ & $0.8 \%$ \\
\hline
\end{tabular}




\begin{tabular}{|l|l|ll|l|l|l|}
\hline retirees & $11.4 \%$ & $\begin{array}{c}39 \\
\%\end{array}$ & $76.6 \%$ & $2.3 \%$ & 0 \\
\hline others & $20.0 \%$ & $\begin{array}{c}24 . \\
\%\end{array}$ & 0 & $56.0 \%$ & 0 & 0 \\
\hline
\end{tabular}

\section{Differentiation between satisfaction and household incomes per capita of rural tourists}

By the items of household incomes per capita,in the 1086 effective questionnaire , there are only 986 copies that are filled with situation of the per capita income, some people would not comment on household income which is could be comprehended.Among them, the people whose family per capita income " $\leqslant 499$ " are 41, "500-999" are 409, "1000-1999" are 409, "2000-2999" are 264, " $\geqslant 3000 "$ are 101 , the data of family per capita income is more representative in Changsha.In the rural tourists whose family have lower income per capita of $" \leqslant 499 "$ or "500-999" ,the number of the people whose option of "very dissatisfied"is zero, and in the option of "not satisfied", the percentage differs from $4.9 \%$ to $5.8 \%$,which are the lowest percentages of this option. That is to say,rural tourists who have lower family income per capita show higher satisfaction in rural tourism shopping as well as the option of "very satisfied". The rural tourists who possess household per capita income of $" \leqslant 499 "$ have the satisfaction of $12.2 \%$, which is the highest percentage.Between the household per capita income of "1000-1999" and "2000-2999" in rural tourists, there exists the similarity in the rural tourism shopping and the percentage of the five options are nearly the same.Yet rural tourists whose household incomes per capita is " $\geqslant 3000 "$ in rural tourism shopping showed more particularity. In option of "very satisfied", the percentage is the lowest that accounts for $6.9 \%$.However, the percentages in "not satisfied" and "very dissatisfied" are low too, which refer to $6.9 \%$ and $1.0 \%$, just go above the family whose per capita income of " $\leqslant 499 "$ or "500-999", these two are lower than "1000-1999" and "2000-2999".See table 5. 
Table 5 The cross analysis of shopping satisfaction and household incomes per capita of rural tourists

\begin{tabular}{|c|c|c|c|c|c|}
\hline & $\begin{array}{l}\text { very } \\
\text { satisfied }\end{array}$ & satisfied & $\begin{array}{l}\text { general } \\
\text { satisfied }\end{array}$ & $\begin{array}{l}\text { not } \\
\text { satisfied }\end{array}$ & $\begin{array}{l}\text { very } \\
\text { dissatisfied }\end{array}$ \\
\hline$\leqslant 499$ & 12. $2 \%$ & $\begin{array}{l}34 \cdot 1 \\
\%\end{array}$ & $48.8 \%$ & 4. $9 \%$ & 0 \\
\hline $500-999$ & 7. $6 \%$ & $\begin{array}{l}38 \cdot 0 \\
\%\end{array}$ & 48. $5 \%$ & $5.8 \%$ & 0 \\
\hline $\begin{array}{l}1000- \\
1999\end{array}$ & 11. $0 \%$ & $\begin{array}{l}34.0 \\
\%\end{array}$ & 45. $0 \%$ & $9.8 \%$ & $0.2 \%$ \\
\hline $\begin{array}{l}2000- \\
2999\end{array}$ & 10. $2 \%$ & $\begin{array}{l}43 \cdot 3 \\
\%\end{array}$ & 37. $5 \%$ & 8. $6 \%$ & $0.4 \%$ \\
\hline$\geqslant 3000$ & 6. $9 \%$ & $\begin{array}{l}43 \cdot 6 \\
\%\end{array}$ & $41.5 \%$ & 6. $9 \%$ & 1. $0 \%$ \\
\hline
\end{tabular}

\section{The basic conclusion and research limitations}

Rural tourists show the following characteristics in differentiation of rural tourism shopping satisfaction in Changsha: at first, on the whole, in the five options including "very satisfied", "satisfied", "general satisfied", "not satisfied" and "very dissatisfied"in rural tourism shopping, these two options of "very satisfied" and "satisfied" account for around 50\% merely,in the case of the present situation of China's tourism shopping, the satisfaction is hasrelatively high.According to the results of the survey, if it were divided by six factors of tourism in the tourist consumption, the cost of the "food" accounted for $50.82 \%$ of total travel cost, the cost of the "transportation" accounted for $22.66 \%$ of total travel cost, while the added costs of "entertainment" and "shopping" were no more than $20 \%$. the present situation and the domestic rural tourism shopping are roughly the same.On the other 
hand,according to the previous investigations, it is concluded that visitors would like to buy the products mainly of rural characteristics, such as native products $(39.38 \%)$, fresh fruit $(20.74 \%)$, fresh aquatic products $(17.15 \%)$, handicrafts $(17.64 \%)$. There are two problems when the visitors buy tourist commodities, one is that there are nearly no rural tourism commodities to buy which reflect the characteristics of the rural,the other is that since we have bought the rural tourism commodities with characteristic, it is the original product without any processing. At the second,according to the concrete stratification of rural tourists, when it comes to the gender of the rural tourists, there was no significant difference between male and female rural tourists shopping, the percentage of women in the "very satisfied" is lower than me and the percentage of women in the "very dissatisfied" is higher than men,which shows that women have a stronger desire on tourism shopping. When it comes to the tourist's age stratification in the rural, each the stratification's shopping satisfaction in rural tourism conforms to their shopping habits basically, but there are certain differentiation, rural tourists who are" $\leqslant 14$ "showed higher satisfaction in the shopping process. While it comes to the cultural degree of rural tourist, it behaves that shopping satisfaction of rural tourists of higher educational level in rural tourism is lower, but the shopping satisfaction of rural tourists with lower cultural level in rural tourism is higher.In consequence,we should pay attention to the quality of tourism commodity, cultural characteristics local characteristics and etc in the development of the rural tourism commodity to improve tourism shopping satisfaction of the rural tourists.As is shown in the occupation of rural tourists, peasants, workers and retirees who have lower income show higher satisfaction in rural tourism shopping,yet the civil servants also show high satisfaction because of the special identity, while the teachers, professional and technical personnel, business managers, students and other professional reported lower satisfaction.In terms of family income per capita,tourists with lower incomes have higher tourism shopping satisfaction and tourists with higher income have higher shopping satisfaction in rural tourism .

In this paper, the objections of the investigation are the rural tourists in the suburban around Changsha, these rural tourists have a strong sense of identity of the local rural tourism commodities, so they perform higher shopping satisfaction in rural tourism. This kind of situation might be a bit different from the current rural 
tourism shopping in China and other tourism shopping situations around other cities in other countries, meantime, it may also has its urban cultural characteristics.In short,the research results represent this kind of rural tourism shopping merely.

\section{References}

[1]Liu Xiaofang. Thinking of the development of rural tourism commodity [J], Journal of Beijing industry and commerce university, 2006. 02.

[2] $\mathrm{Wu}$ Ganying. Tourists psychology and production and sales of the tourism commodity [J], Tourism economy, 1992.

[3] Ding Jihua. Theoretical thoughts that Shanghai built the travel distribution [J], Tourism Tribune, 1997.04.

[4] Huang Jiyuan. Marketing strategies of tourism commodity in Kunming [J], Yunnan institute of finance and trade journals, 1999.01.

[5] Zhang Lili. Cultural connotation by packaging design of tourism commodity [J], China packaging industry, 2003. 12.

[6] Yan Min. Tourism thinking about tourism products [J], Tourism research and practice, 2000.03.

[7] Shi Meiyu. Theoretical thinking related to the research of tourism shopping [J], Tourism Tribune, 2004.01.

[8] Miao Xueling. Systematic research on the tourism shopping [D], Shaanxi Normal University, master thesis, 2002.

[9] Shi Meiyu. China's tourism shopping research [D], Graduate School of Chinese Academy of Social Sciences, Ph.D. Thesis, 2003.

[10] Wu Bihu.Planning principle of regional tourism [M], China Travel \& Tourism Press, 2001. 5. 